\title{
Apresentação de resultados de investigação *
}

\author{
Um manual para químicos que apresentam trabalhos em reuniões \\ internacionais de Química
}

A tradução deste artigo é apresentada na sequência da publicação feita por duas vezes em Chemistry International $\left(\mathrm{n} .{ }^{\circ} 2,1980 ; \mathrm{n}^{\circ}{ }^{3}\right.$, 1981), jornal da IUPAC, bem como da tradução em L'Actualité Chimique (n. $\left.{ }^{\circ} 2,1981\right)$ e em Química Nova (vol. 6, n. $\left.{ }^{\circ} 1,1983\right)$. $\mathrm{O}$ facto de ser inserida a repetição do artigo no mesmo jornal foi consequência do número de pedidos de cópias recebido (mais de 5000 ) e atesta $o$ interesse que $o$ artigo despertou.

Agradece-se a Chemistry International a autorização dada para tradizir este artigo e publicá-lo no Boletim da $S P Q$ para beneficiar aqueles que, em Portugal, se dedicam quer à investigação, quer ao ensino da Química, sobretudo os que não têm acesso fácil a publicaçð̌es da IUPAC.
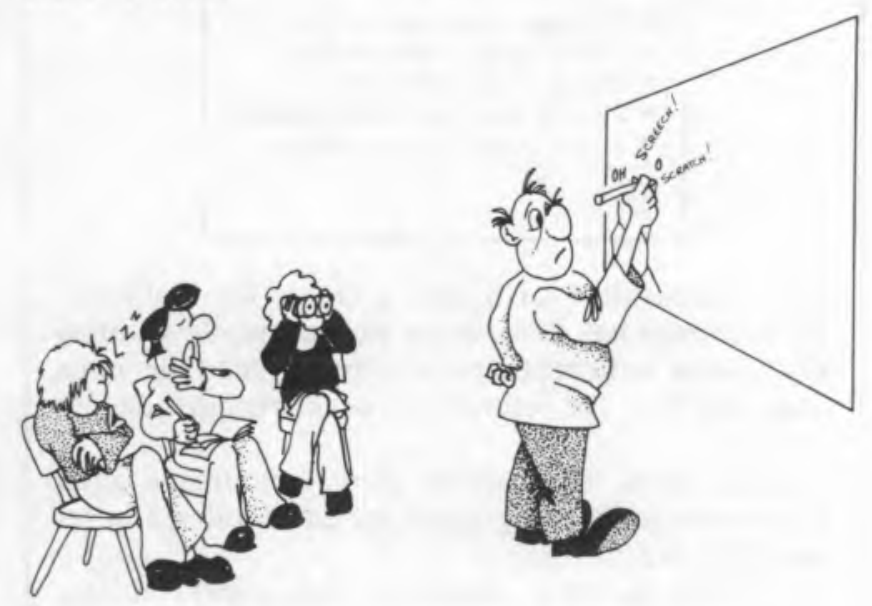

Não há nenhum método de comunicação de resultados individuais de investigação que tenha maior impacto e desperte mais atenção do que uma apresentação frente a frente numa reunião de Quimica de alto nível - seja uma conferência plenária, apresentação de painéis ou apresentação oral de curta duração. Mas, por outro lado, nada pode ser mais aborrecido do que um orador que não tenha organizado o seu material, que mostre diapositivos repletos de dados que mascaram conclusøes singificativas e que ultrapasse o tempo disponivel falando com uma voz monótona.

O presente artigo é um guia para o auxiliar a apresentar os resultados da sua investigação, as suas conclusões e pontos de vista em reuniōes de Química. A maioria das sugestões é simples... talvez óbvia. São apresentadas sugestões para preparar a sua apresentação e ressalta erros que devem ser evitados. Mesmo assim estes erros são repetidos em praticamente todas as reuniões, reduzindo o interesse e compreensão da audiência. A atenção a estes pontos pode tornar o seu trabalho melhor compreendido e reconhecido por químicos através do mundo.

Este guia é baseado em três ensaios escritos por Guy Ourisson, secretário-geral da IUPAC e Professor no Instituto de Química Université Louis Pasteur em Estrasburgo, França.

\section{APRESENTAÇÃo ORAL}

Comece a falar... mas não agora. Acaba de lhe ser dada a palavra pelo presidente da mesa. Espere que o encarregado da projecção tenha preparado os seus diapositivos. Aguarde o momento em que possa falar com segurança e, então, comece.

Comece por referir o que vai falar, em seguida fale sobre isso e, por fim, resuma o que foi dito.

Nunca admita que alguém na audiência seja seu fã, conheça o seu trabalho, esteja familiarizado com as suas publicações e esteja à espera que divulgue apenas resultados novos. Coloque sempre o seu assunto numa perspectiva global e explique por que o seleccionou. Descreva sucintamente os seus métodos e resultados e descreva claramente as suas conclusões.

Durante a apresentação, bem como na discussão, fale para a pessoa que está sentada no local mais afastado e não para o presidente da mesa ou para os seus colaboradores sentados nos lugares da frente. Pode pressupor com confiança que este ouvinte no fundo da sala não tem competência na sua área de trabalho mas que espera ser esclarecido. Certifique-se que ele o ouve e que o compreende. Nunca fale para o quadro. Se o auditório estiver equipado com microfone e alto-falantes, evite o ruído estridente provocado pela captação do ruído de um dos alto-falantes pelo microfone: não deixe que o microfone se aproxime do alto-falante mais próximo. Fale sempre perto, mas não colado ao microfone e nunca, nunca toque, mova ou bata nele. Ou então, esqueça o microfone e fale alto.

Se a sua apresentação vai ser acompanhada de tradução simultânea, entre em contacto com o tradutor antes da hora. Dê-lhe um texto relacionado com a conferência ou uma lista com as palavras mais específicas que vai utilizar. Ofereça-lhe antecipadamente a sua ajuda.

Nunca leia um texto: não há nada mais aborrecido. Se não se sentir seguro, use diapositivos com texto, para o auxiliar - e, novamente, não leia textualmente mas limite-se a comentá-los. É muito provável que todos na audiência saibam ler...

Quando ditas em público, certas palavras não ficam na mente de ninguém. Nunca as empregue sem as ter escrito no quadro ou num diapositivo. Nomes estrangeiros podem ser pronunciados de muitas maneiras. Datas

* Tradução de Mariana P.B.A. Pereira, Departamento de Educação da Faculdade de Ciências de Lisboa.

Cumpre aqui à Direcção do Boletim acusar-se como único responsável pela publicação tardia deste texto que o seu tradutor, e muito prezado colaborador, nos entregou em data oportuna. Felizmente que o texto em causa, tal como o bom vinho, ganha com o tempo. Dai que a sua publicação não tenha perdido, pelo contrário, a sua actualidade. 
e valores numéricos também devem ser escritos: numa audiência internacional em que se refira " 25 ", alguns podem confundir "fifty two" com "twenty five" ("fünf und zwanzig'). De qualquer modo, é melhor não empregar valores numéricos a não ser que entrem directamente na sua discussão. De contrário, quem é que na audiência vai ligar importância ao valor de um ponto de fusão, rotação específica ou deslocamento químico de r.m.n.?

Outro ponto a evitar: nunca empregue um nome sistemático de acordo com a IUPAC, soa mal. Nomes segundo a IUPAC não foram propostos para serem usados desta maneira. Números de passaporte também são sistemáticos, não são ambíguos e são óptimos descritores de individuos, mas quem é que vai chamar a sua namorada pelo número do passaporte? $\mathrm{E}$, de qualquer modo, a audiência ficará muito bem informada se disser "esta cetona insaturada..." enquanto se refere à fórmula que está no diapositivo ou no quadro.

Não exceda o tempo disponível. É uma boa ideia fazer uma apresentação prévia para alguns amigos que o possam criticar e que cronometrem o tempo. Diz-se que um novo Presidente ou Primeiro-Ministro tem 100 dias para mostrar o que pode fazer. Um conferencista tem 20 minutos, quando muito. Se a apresentação está marcada para durar 45 minutos, os últimos 25 minutos só serão úteis se conseguiu interessar a audiência nos primeiros 20 minutos. Se for um excelente orador, ninguém vai notar que ultrapassou o limite de tempo de alguns minutos. Mas se balbuciar após o limite, pode ter a certeza que vai antagonizar o orador seguinte, o responsável pela sessão e o resto da audiência. Obedeça automaticamente às luzes de aviso, se em uso, ou use relógios com alarme.

$\mathrm{E}$, agora, algumas palavras sobre setas luminosas que se destinam a mostrar um ponto no diapositivo e em seguida a desaparecer. Uma seta luminosa será mais visível em qualquer outra superfície além do écran de projecção; desligue-a quando não estiver em uso. De contrário estará a chamar a atenção da audiência para a parede de sala, para o tecto ou para um vaso de plantas.

Quando chegar ao fim da sua palestra conclua brevemente, de modo claro e explícito. A audiência deve saber quando aplaudir ou, pelo menos, quando acordar. Finalmente, se tem de falar em inglês e não domina bem a língua, peça auxílio a um colega de língua inglesa pelo menos para corrigir as palavras-chave que vai usar constantemente durante a palestra.

\section{APRESENTAÇ̃̃o DE DIAPOSITIVOS}

Os diapositivos são a maneira mais fácil de transmitir informação nas condições de uma apresentação oral. $\mathrm{O}$ melhor modo é, provavelmente, o giz e o quadro, mas o seu uso em simpósios requer experiência, espaço amplo no quadro e um tópico apropriado. É insuperável quando é bem feito, mas geralmente nẩo é recomendável.

Os diapositivos são muito valiosos para realçar pontos importantes da sua apresentação oral e para mostrar material que não possa ser explicado com facilidade. Mas os diapositivos não devem ser empregados para reproduzir o que você diz e nunca devem ser lidos do écran.

Os diapositivos devem ser legíveis e inteligíveis. Um diapositivo que não possa ser lido por qualquer um na audiência, incluindo as pessoas da última fila, não deve ser projectado.

A primeira condição para que um diapositivo seja legível é que ele apareça integralmente no écran. Isto parece trivial, mas é vulgar ver apresentadores que inserem diapositivos "verticais" no meio de diapositivos orientados horizontalmente e assim aqueles são projectados no tecto. Isto pode ser evitado, preparando todos os diapositivos para serem projectados horizontalmente. Outra condição é as letras serem grandes e as linhas mais grossas do que para uma figura impressa. Qualquer diapositivo que não possa ser lido o olho nu na sua mão, provavelmente não será legível quando for projectado num écran. Este é um teste rigoroso para a legibilidade; é simples e funciona.

Este diapositivo visto a uma distância de $25 \mathrm{~cm}$ dá uma indicação de como ele irá aparecer no écran de projecção, visto dos últimos lugares de uma sala de conferências.

\begin{tabular}{|l|}
\hline - Prepare diapositivos simples \\
- Use o espaço com eficiência \\
- Realce a sua mensagem \\
- Poucas palavras, letras grandes \\
- Limite o . $^{\circ}$ de diapositivos \\
\hline
\end{tabular}

Em "Preparation of Slides; a Guide for Authors" da International Federation of Automatic Control são dadas indicaçð̃es para a preparação de bons diapositivos. De entre as suas recomendações tem-se:

(1) Um bom diapositivo deve comunicar uma mensagem única e significativa em apoio da apresentação oral.

(2) Normalmente é vantajoso simplificar tabelas, gráficos, diagramas e desenhos.

(3) Só são recomendadas tabelas se o seu conteúdo não puder ser traduzido graficamente.

(4) Não reproduza material de publicaçōes impressas, excepto quando for material apropriado. $\mathrm{Na}$ maior parte dos casos, as ilustraçðes impressas apresentam demasiados pormenores.

(5) Use um escantilhão (normágrafo) para as letras do texto. Deixe espaço adicional entre as palavras e linhas.

Outra sugestão útil é a de colocar uma etiqueta (auto-adesiva) com um número no canto inferior esquerdo do diapositivo (na posição em que o diapositivo é visto). Isto simplifica a ordenação dos diapositivos e assegura que sejam projectados de forma correcta. Quando o diapositivo for colocado correctamente no projector, a etiqueta numerada ficará coberta pelo polegar direito do operador.

Para todo o trabalho de arte-final, use, suma página padrão $\mathrm{A} 4,180 \times 240 \mathrm{~mm}$, nunca um formato maior. Numa página deste tamanho, pode escrever as fórmulas com dimensões adequadas, empregando escantilhões comerciais (feitos, por exemplo, pela Verlag Chemie, Merck, Darmstadt, Molin, etc.). 
Limite a quantidade de informação de cada diapositivo. Procure pôr um "bit" de informação por diapositivo e não hesite em desmembrar um conjunto de dados em dois diapositivos. Para evitar a acumulação de informação em cada diapositivo não exceda $20-25$ palavras por diapositivo.

Não inclua informações sobre as quais não vai tecer comentários - nomenclatura, pontos de fusão e referências bibliográficas. Pense duas vezes antes de mostrar um espectro de r.m.n. ou um cromatograma (é mesmo uma novidade?). Tire ds seus diapositivos todo o ruído desnecessário, isto é, informação sem propósito aparente. Nunca mostre tabelas numéricas (embora o possa fazer sem problemas, se a tabela for suficientemente simples e dentro do limite de $20-25$ palavras/ /diapositivo).

Diapositivos legíveis não implicam um trabalho de profissional; letras decalcáveis (tais como Letraset, Decadry, etc.) permitem que os químicos façam desenhos e legendas com um toque profissional. Letras e esquemas feitos à mão podem também ser eficazes e elaborados com mais facilidade mas deve ter uma escrita legível e alguma queda para o desenho. Experimente uma vez e faça-os avaliar por amigos antes de os expor à audiência.

Os diapositivos são especialmente valiosos se vai proferir uma palestra numa lingua que não domina totalmente. Eu poucas palavras, pode resumir o problema, os métodos, os resultados e as conclusões. Erros gramaticais podem ser eliminados previamente pela avaliação e correcção dos diapositivos.

Cada tipo de diapositivo apresenta vantagens e desvantagens. Por exemplo diapositivos com figuras em preto sobre fundo branco mostram mais poeira do que diapositivos de branco em preto, mas são mais fáceis de ler. A maior limitação na qualidade de qualquer sistema de diapositivos é a experiência, o equipamento e o cuidado do fotógrafo. Consulte-o; ele sabe que tipo de material é melhor reproduzido e mais legível. Também pode ler artigos que dão orientação sobre isto (o folheto "Slides with a purpose" pode ser obtido gratuitamente no Dep. 55Z, Kodak Inc., Rochester N. Y. 14650 USA).

O mesmo diapositivo pode ser necessário duas ou mais vezes durante a conferência. Providencie duas ou mais cópias em vez de esperar que o encarregado da projecção encontre, às escuras, o "diapositivo n. ${ }^{\circ} 15$ ".

Identifique a orientação dos seus diapositivos por meio de uma etiqueta ou marca na armação, facilmente identificável e bem visível no escuro. Isto é absolutamente necessário se só se dispõe de um projector e pode ser valioso se se usar um projector automático. Bem antes da sua apresentação, entre em contacto com as pessoas encarregadas da sala de conferências. Apresente-se ao encarregado da projecção; muito do seu sucesso dependerá dele. Pergunte como é que ele prefere que lhe peça o diapositivo seguinte e veja se há suportes disponiveis. Coloque os diapositivos no suporte, verifique a sua orientação e decida se é preferivel o escurecimento total ou parcial da sala. Verifique a qualidade e o tamanho das imagens na tela. Se os diapositivos se mostrarem inaceitáveis para as condições disponiveis, a sua conferência ainda poderá ser salva por um rectro-projector ou pelo giz no quadro.

É espantoso como mesmo alguns oradores com experiência ficam aparentemente indiferentes ao deixarem um encarregado de projecção cansado arruinar a apresentação, ao mostrar diapositivos mal focados, por or- dem errada e após pedidos repetidos do diapositivo seguinte. Ainda pior são o tempo e a atenção perdidos pela audiência enquanto se experimentam as sete orientações erradas possiveis para um diapositivo, antes de encontrar, por acaso, a posição correcta. Geralmente, estes problemas evitam-se, se houver uma conversa prévia com o encarregado da projecção.

A ocasião que poderá dar mais problemas durante um simpósio é a Conferência de Abertura. É nesta altura que os organizadores se podem aperceber que o écran é pequeno, que não há giz de cores nem lâmpada sobressalente para o projector, de que a iluminação não se pode escurecer parcialmente ou que o microfone não funciona. Não desepere. Se for o conferencista da abertura não precisará de conselhos. Sem dúvida a sua habilidade a sobreviver a tais problemas foi um dos factores que contribuiu para o alto conceito que lhe dispensa a comunidade quimica e para o convite que lhe foi feito para apresentar a conferência da abertura.

Exemplo de uma ilustração de má qualidade para ser projectada:

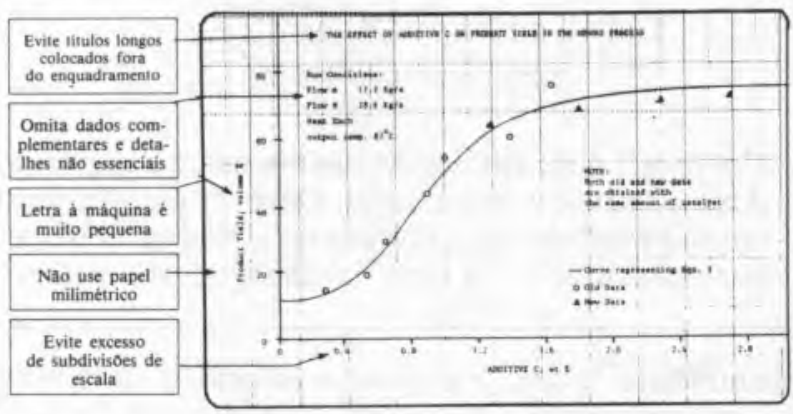

Os dois diapositivos apresentam o mesmo material, mas o inferior foi re-desenhado para maior simplicidade e clareza. Os pormenores explicativos e dados acessórios foram omitidos, podem ser apresentados oralmente se necessário ou se forem pedidos (adaptado de "Preparation of Slides; a Guide for Authors').

Exemplo de uma ilustração de boa qualidade para ser projectada:

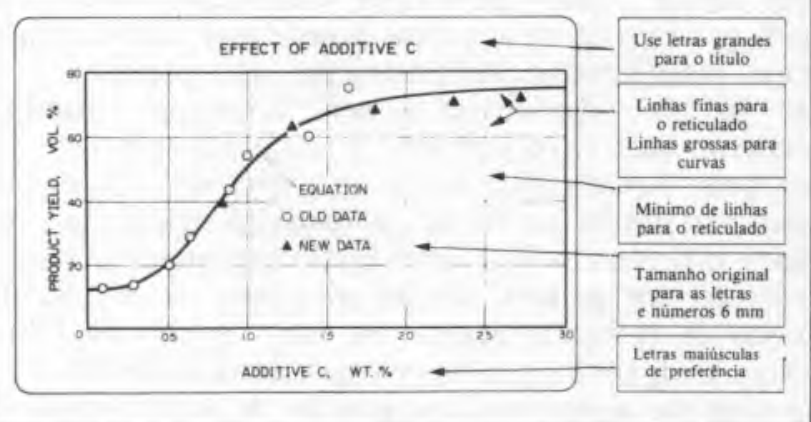

\section{APRESENTAÇÃO DE CARTAZES ("POSTERS")}

As sessōes de cartazes têm ganho larga aceitação para a comunicação de informação e motivação para a discussão em congressos, fornecendo uma alternativa viável às comunicações orais de curta duração - uma 


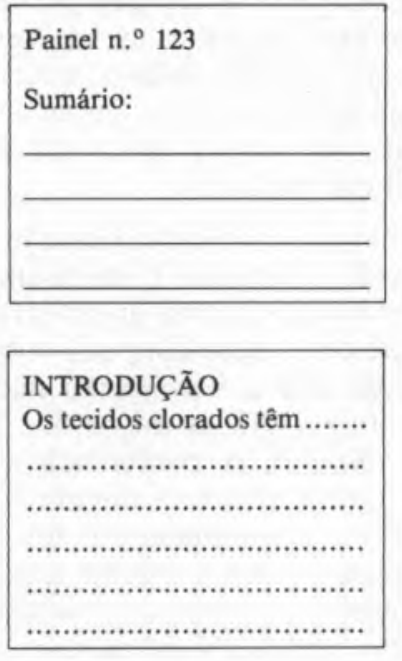

\section{TECIDQSS CLORADOS COMO MATÉRIA-PRIMA PARA PESTICIDAS C. LEITE QUEIMADO (DEP. QUIMICA, UNIV. DE FUGACIDADE, FUGACIDADE, ELLOBOVIA)}
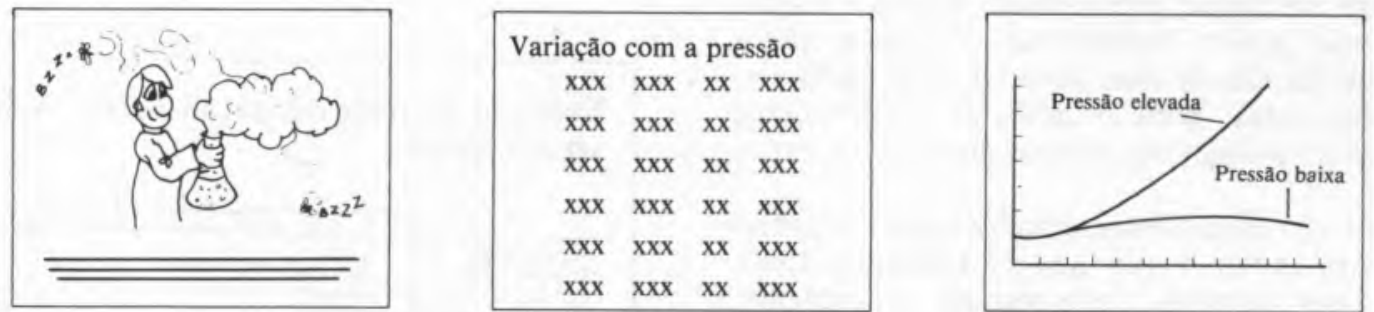

Um painel deve apresentar sucintamente a importância do projecto, as informaçðes básicas essenciais e os resultados e conclusס̃es dos autores. Deve ser auto-explicativo, embora os autores devam estar preparados para apresentar dados adicionais e discutir os métodos. O painel deve ser disposto de um modo claro, com letras grandes para fácil visualização. A uma distância de três metros, o painel deve apresentar-se como este.

oportunidade maior à discussão informal, permitindo que os autores experimentem métodos originais de apresentação. Os autores podem apresentar amostras de substâncias-chave, dados, trabalhos publicados, fotografias das suas aparelhagens, de trabalhos de campo ou deles próprios. E importante reconhecer qeu as sesssões de painéis não são relegadas para comunicar investigaçð̃es de segundo plano, mas permitem que interesses de investigação comuns sejam discutidos individualmente ou em pequenos grupos.

A maioria dos quadros, desenhos e ilustrações utilizados em painéis podem ser bastante semelhantes àqueles que seriam usados para fazer diapositivos embora sejam geralmente menos bem acabados e feitos com linhas mais grossas. As ilustrações não precisam - e, na verdade, não devem - ser "artísticas". Produza material ilustrativo simples. O simples emprego de cores pode proporcionar realce com eficiência. Os diagramas não devem ser feitos em material rígido, pois isto pode dificultar a sua montagem nos quadros para a exibição dos painéis. Talvez seja bom ter à mão um bloco de rascunho e uma ou duas canetas de feltro. $\mathrm{O}$ que pode ser incluído numa apresentação de painéis fica limitado apenas pela imaginação do autor (dentro do limite de espaço disponível). Muitos autores começam por elaborar uma etiqueta contendo o título, o nome dos autores e o número atribuido ao painel, de modo que este seja facilmente identificável (a etiqueta pode também ser fornecida pelos organizadores da conferência). Pode incluir também o horário em que os autores estarão disponiveis para discutir os painéis. Normalmente afixa-se uma cópia do resumo. A etiqueta e as ilustraçð̄es são montadas numa placa de madeira, geralmente com pu- naises. Se precisar de fita-cola, talvez seja necessário levá-la consigo. É aconselhável ter disponível todas as figuras, tabelas e equaçōes pertinentes, mesmo que não planeie afixá-las. Os paínéis devem ser preparados pelos autores antecipadamente e devem ser montados e removidos no horário afixado previamente pelos organizadores da conferência. A maioria das conferências tem "'assistentes para as sessões de painéis"' prontos a responder a dúvidas e a ajudar sempre que surgem problemas técnicos.

Os painéis devem ser geralmente preparados de modo a que sejam compreendidos mesmo na ausência dos autores e sem um estudo do resumo. As secções podem ser subdivididas em SUMÁRIO (ou resumo), INTRODUÇÃO, RESULTADOS e DISCUSSÃO. O SUMÁRIO deve indicar os resultados e as conclusões pertinentes. A INTRODUÇÃO deve dar as informções básicas e indicar o propósito do estudo em relação a trabalhos anteriores no mesmo campo. A secção de RESULTADOS pode ser dividida em subtítulos, cada um indicando um resultado importante. Geralmente, inclui-se o menor número de resultados, apenas os suficientes para justificar as conclusões. Um painel sobrecarregado de resultados raramente atrai a atenção. De facto, não se é obrigado a preencher todo o espaço disponível com as informações! Finalmente, a secção de DISCUSSÃO deve conter a interpretação dos resultados e apresentar o seu significado, mesmo que seja especulativa - resumindo as conclusōes de uma forma fácil de relembrar.

É importante planear cuidadosamente a utilização óptima do espaço do painel. Pode ser útil subdividir em secçб̃es de tamanho padronizado (por exemplo, 9 secções de 